\title{
Live births, natural losses, and elective terminations with Down syndrome in Massachusetts
}

\author{
Gert de Graaf, PhD', Frank Buckley ${ }^{2,3}$ and Brian G. Skotko, MD, MPP 4,5
}

\begin{abstract}
Purpose: No studies to date have reported an estimated number of live births, elective terminations, and natural losses (miscarriages and stillbirths) for Down syndrome (DS) in Massachusetts (MA). These numbers would be helpful to estimate how many expectant parents of children with DS need support and the number of live-born children with DS who require services.
\end{abstract}

Methods: Combining robust data sets, including the Annual Reports of the MA Birth Defects Monitoring Program, we estimated the number of live births, elective terminations, and natural losses with Down syndrome from 1900 to 2010.

Results: The live birth prevalence for DS in MA for the most recent years for which data are available (2006-2010) was estimated at 12.4 per 10,000 live births, with a total of approximately 94 live births annually. During this period, an estimated 126 DS-related elective pregnancy terminations were performed in MA annually. As of 2008, the estimated rate at which live births with DS was reduced as a consequence of DS-related elective pregnancy terminations was $49 \%$.

Conclusion: The reduction of live births with DS is significantly higher in MA than in the rest of the United States as a whole. However, ethnic and racial differences in reduction rates were similarhighest for Asians/Pacific Islanders, followed by non-Hispanic whites, non-Hispanic blacks/Africans, and Hispanics.

Genet Med advance online publication 14 April 2016

Key Words: Down syndrome; incidence; prevalence; terminations; trisomy 21

\section{INTRODUCTION}

As prenatal testing for Down syndrome (DS) rapidly evolves, the resource and advocacy efforts in Massachusetts (MA) keep pace. Health-care professionals, family advocates, and elected officials have worked collaboratively to ensure that expectant couples have access to up-to-date and accurate information about DS, which is a requirement for informed decision making. The Massachusetts General Hospital Down Syndrome Program established a prenatal clinic where expectant parents can learn more about DS from a multidisciplinary team. ${ }^{1}$ The Massachusetts Down Syndrome Congress (MDSC), a statewide nonprofit, nongovernmental organization, developed a robust Parents First Call Program, in which trained parents who have children with DS are available 24 hours per day, 7 days per week, to connect with new or expectant parents. ${ }^{2}$

Education of health-care professionals has also been a focus of the synergistic effort. The MDSC asked health-care providers on its Medical and Science Advisory Board to give grand rounds about DS at all of the MA maternity hospitals. ${ }^{3}$ The organization also joined prenatal testing companies and the MA government in sponsoring an online webinar for healthcare providers about how best to explain a prenatal diagnosis of DS to expectant parents. ${ }^{4}$

In 2012, the MA legislature also passed a landmark bill, Act Relative to Down Syndrome Genetic Test Results (H3825), which requires health-care providers to give new or expectant parents of children with DS the latest, culturally appropriate information about what it means to have a child with DS. ${ }^{5}$ With funding from the state legislature, the MDSC is able to provide the Joseph P. Kennedy Jr. Foundation's booklet, Understanding a Down Syndrome Diagnosis, to all expectant women and their providers in MA. ${ }^{6}$ The bill also requires that new and expectant parents be provided with contact information for the MDSC. Fourteen other states have since passed similar bills modeled after the MA legislation.

With all of these advocacy efforts, however, no studies to date have reported an estimated number of live births, elective terminations, and natural losses (miscarriages and stillbirths) for DS in MA. Not until 2011 did the Massachusetts Center for Birth Defects Research and Prevention (MCBDRP) begin to collect data regarding elective terminations.

Recently, de Graaf et al. ${ }^{7}$ provided estimates for live births, natural losses, and elective terminations for the United States as a whole. Before 2002, live birth prevalence was based on a study by Shin et al., ${ }^{8}$ who presented surveillance data from 1979 onward. For the period 2002-2010, de Graaf et al. made use of the data of the National Birth Defects Network.

In this article, we focus on MA and, in doing so, provide a blueprint for other states interested in calculating trends in live births, elective terminations, and natural losses for DS. These

${ }^{1}$ Dutch Down Syndrome Foundation, Meppel, The Netherlands; ${ }^{2}$ Down Syndrome Education International, Kirkby Lonsdale, Cumbria, UK; ${ }^{3}$ Down Syndrome Education USA, Newport Beach, California, USA; ${ }^{4}$ Division of Medical Genetics, Department of Pediatrics, Massachusetts General Hospital, Boston, Massachusetts, USA; ${ }^{5}$ arvard Medical School Boston, Massachusetts, USA. Correspondence: Brian Skotko (bskotko@mgh.harvard.edu) 
numbers are important for planning services and can provide a baseline from which future trends for live births with DS at the state level can be estimated. To calculate "population prevalence" for people with DS in MA, these estimates are also needed. For this last reason, we chose not to limit our estimations of live birth prevalence to only recent years.

In this study, we estimated the prevalence of DS in MA from 1900 to 2010 by combining multiple publicly available data sources. For the years after 1974, when prenatal diagnostic testing was introduced, we also estimated the number of live births, elective pregnancy terminations, and natural losses with DS. In addition, for the first time, we calculated the reduction percentage for DS in MA-that is, how many live births with DS were reduced consequent to elective terminations.

\section{MATERIALS AND METHODS}

\section{Estimating nonselective live birth prevalence for DS}

In estimating "nonselective live birth prevalence" - that is, expected birth prevalence without elective terminations of pregnancy-we made use of the model for maternal agespecific chances for a child with DS, as developed by Morris et al. ${ }^{9}$ This model is based on the National Down Syndrome Cytogenetic Register in the United Kingdom, a registry with a high level of ascertainment. ${ }^{9,10}$ In addition, this model has been used to accurately predict the live birth prevalence of DS in the Netherlands between 1986 and 2007. ${ }^{11}$

According to some studies, the chance of giving birth to a baby with DS might vary between mothers from different racial or ethnic backgrounds. ${ }^{12-16}$ However, other researchers suggest that these racial differences might be explained by disparate preferences of prenatal testing ${ }^{17}$ or by ascertainment bias. ${ }^{13,16}$ Therefore, we assumed that this chance does not vary between different countries or between mothers from different racial or ethnic backgrounds. In addition, the model used by Morris et al. is based on data from the United Kingdom, and both the UK population and the MA population are predominantly white. ${ }^{18}$

The difference between nonselective live birth prevalence and actual live birth prevalence can be used to estimate the number of DS-related elective terminations of pregnancy. We consider this a more accurate estimate than using information on elective terminations as reported in surveillance programs because there appears to be a considerable underascertainment of these terminations in surveillance programs. ${ }^{7}$ By using the same method as this current study, de Graaf et al. ${ }^{7}$ predicted 3,100 DS-related elective terminations in the United States as of 2007. By contrast, for the period 2006-2010, on the basis of counts in surveillance programs by Mai et al., ${ }^{19}$ this number would be estimated at approximately 700 , suggesting significant underascertainment in these programs. Table 1 lists our sources for data on live births by maternal age in MA.

\section{Estimating live birth prevalence of DS in MA}

Prior to 2000. For the period before 2000, no reliable data on live births with DS in MA are available. Hence, for the period prior to 1983, we assumed that the reduction percentage resulting from terminations in MA was similar to that in the United States as a whole, as modeled by de Graaf et al. ${ }^{7}$ (2015) — that is, $0 \%$ before 1969 and rising to $10 \%$ in 1980 and $20 \%$ in 1983 . For the years between 1983 and 2000, we interpolated the reduction percentages (from 20\% in 1983 to an average of 52\% between 2000 and 2004 in MA) and applied these annual estimates to the nonselective live birth prevalence for DS in the corresponding year.

2000-2010. We obtained data on live births with DS in MA for 2000-2010 from the Annual Reports of the MA Birth Defects Monitoring Program (http://www.mass.gov/dph/birthdefects). For the years 2002-2003, only data on pooled live births and stillbirths were available. During 2000-2001 and 2004-2005, $96.2 \%$ of pooled births of children with DS were live births, so we corrected by multiplying the reported total number for 2002-2003 by 0.962. Data are available for MA for 1999 from the Birth Defects Surveillance Data from Selected States, 1995-1999, of the National Birth Defects Prevention Network (http://www. nbdpn.org). However, the counts of cases of DS in 1999 are so much lower than in the following years-and the same applies to some of the other more frequent birth defects-that we speculate that there might have been some underascertainment in 1999 because it was the first full year in action for the MA surveillance program. Therefore, we refrained from using data from 1999.

For the years after 1999, we expect that the MCBDRP will have a very high level of ascertainment. Because MCBDRP uses an active surveillance system, live births with DS are based not on birth certificates alone but are reported to these registers by health-care professionals from diverse disciplines. Birthing hospitals and other pediatric care centers across the state-and in Rhode Island, near the MA state border (because some MA residents go there to give birth) - submit to the MCBDRP monthly discharge lists their birth defect diagnoses. Nursery and neonatal intensive-care personnel also report cases of birth defects to the MCBDRP. Medical record abstractors are then sent out to each hospital to collect important demographic and diagnostic information from hospital records. A clinical geneticist then reviews the cases. With such a thorough data-collection approach, almost all, if not all, live-born children with DS will be identified.

\section{Estimating DS-related elective pregnancy terminations}

Estimating procedures were fully explained in our previous publication. ${ }^{7}$ To estimate the number of DS-related elective pregnancy terminations, we calculated the difference between the number of nonselective live births and the number of live births with DS. We divided this number by 0.73 to account for an estimated 27\% natural loss rate from 1990 onward because de Graaf et al. ${ }^{7}$ estimated on the basis of the National Down Syndrome Cytogenetic Register database that for every 100 elective terminations of pregnancies diagnosed with DS, 73 live births of DS were prevented. We assumed a $24 \%$ natural loss rate before 1990 because most procedures would have been amniocenteses in this period. Morris et al. ${ }^{20}$ reported an average loss rate of $23 \%$ for pregnancies with DS following amniocenteses, and Savva et al. ${ }^{21}$ reported an average of $25 \%$. 
Table 1 Sources of MA data on births by maternal age and adjustments made

\begin{tabular}{|c|c|c|}
\hline Period & Source $^{a}$ & Notes \\
\hline 1920-1930 & $\begin{array}{l}\text { Vital Statistics Rates in the } \\
\text { United States 1900-1940 }\end{array}$ & $\begin{array}{l}\text { Age-specific fertility rates in MA and age distribution of the female population in MA used to } \\
\text { estimate maternal age distribution in 5-year bands for } 1920 \text { and 1930. In estimating nonselective } \\
\text { DS prevalence, we interpolated years in between (1921-1929) }\end{array}$ \\
\hline 1990-2010 & $\begin{array}{l}\text { Birth Data Files, National Center } \\
\text { for Health Statistics, CDC }\end{array}$ & Single-year age bands-no adjustments \\
\hline
\end{tabular}
CDC, Centers for Disease Control and Prevention; DS, Down syndrome; MA, Massachusetts.

${ }^{a}$ All data and documents used can be found at http://www.cdc.gov/nchs/products/vsus.htm or http://www.cdc.gov/nchs/data_access/Vitalstatsonline.htm.

\section{Live birth modeling with and without elective pregnancy terminations}

For MA, we estimated the number of live births with DS, elective pregnancy terminations of fetuses with DS, and natural losses between a gestational age of 10 weeks and expected date of birth. We did this for both the actual situation and a hypothetical situation in which there were no DS-related elective terminations. The estimation procedures for constructing these scenarios were described in detail by de Graaf et al. ${ }^{7}$ In short, for each year we estimated the number of DS births without DS-related elective terminations by applying the model for maternal age-specific chances for a child with DS, as developed by Morris et al., ${ }^{9}$ to the number of births by maternal age in the MA general population. In addition, we estimated the number of fetuses with DS at 10 weeks gestation and the number of fetal loss between 10 weeks and birth in this nonselective scenario by applying a correction factor for natural loss for each maternal age group, based on work by Savva et al., ${ }^{21}$ to the estimated number of live births with DS (in absence of terminations) by maternal age group. For the actual scenario, from 2000 onward, the number of live births with DS was based on the MCBDRP. For the years before 2000, we constructed the live births on the basis of an interpolation of reduction percentages, as explained above. The number of reduced live births of children with DS can be estimated by calculating the difference between the estimated number of live births in the nonselective scenario and the actual scenario. The number of elective terminations (in the actual scenario) can be estimated on basis of the number of births reduced by applying a correction factor for natural loss. Natural losses in the actual scenario can be estimated by subtracting the estimated number of live births and elective terminations from the estimated number of fetuses with DS at 10 weeks.

\section{Differences by race/ethnic group}

In addition, we analyzed the available data by the reported race/ ethnic groups (non-Hispanic, whites, non-Hispanic blacks/ Africans, Hispanics, Asians/Pacific Islanders) for 2006-2010. Data on American Indians were not available; however, there are very few births of American Indians, in general, in MA (See Supplementary Table S4 online).

\section{RESULTS}

For MA, we estimated the number of nonselective live births and the number of live births with DS (Figure 1 and Supplementary Table S1 online) and the nonselective live birth and live birth prevalence (Figure 2 and Supplementary Table S2 online) for 1900-2010. In addition, we present the results for the two scenarios as explained in the Materials and Methods section (Figure 3 and Supplementary Table S3 online).

\section{Impact of elective terminations of pregnancies}

For MA, the live birth prevalence for 2006-2010 was estimated at 12.4 per 10,000, or 1 in 810 , with approximately 94 live births annually. During this period, an estimated 126 DS-related elective pregnancy terminations were performed annually. Without DS-related elective pregnancy terminations, approximately 186 children with DS would have been born annually. Overall, in MA, an estimated $49 \%$ of potential live births with DS were selectively terminated in recent years, which is slightly less than the estimate of $52 \%$ for 2000-2004. According to our model, the annual number of DS-related elective pregnancy terminations increased sharply in 1970-2004, starting with fewer than 10 in the 1970s and reaching approximately 142 in 2004. In the late 2000 s, these numbers decreased slightly, to an estimate of 117 in 2010.

\section{Differences by race/ethnic group}

For the most recent 5-year period (2006-2010), we present estimations of nonselective and actual live births by race/ethnic group in Table 2. Reduction percentage estimates differ greatly by race/ethnic group-highest for Asians/Pacific Islanders (60\%), followed by non-Hispanic whites (54\%), non-Hispanic blacks/Africans (29\%), and Hispanics (13\%) (Table 2).

\section{Confidence intervals for nonselective live birth prevalence and live birth prevalence}

Using the same procedures as those described by de Graaf et al., we estimated that the $95 \%$ confidence intervals (CI) of our nonselective live birth prevalence for DS in MA were, on average, within 2.9 live births with DS per 10,000 live births-that is, on average, annual nonselective prevalence might be 2.9 per 10,000 


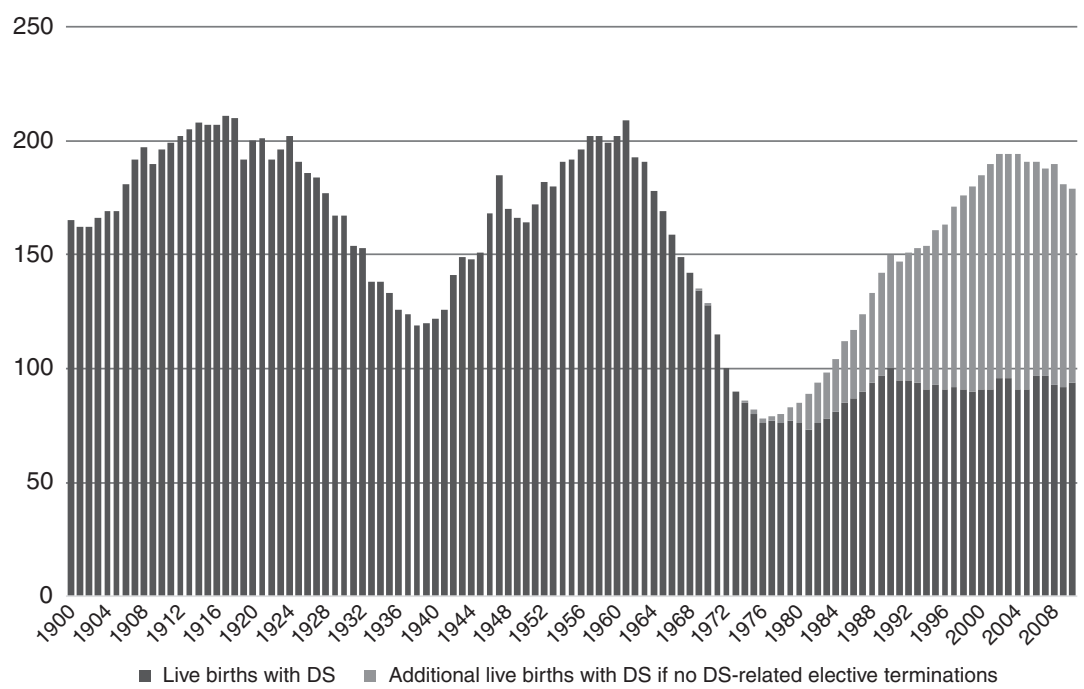

Figure 1 Estimated annual live births with DS in MA and additional live births if there were no DS-related elective terminations during 19002010. DS, Down syndrome; MA, Massachusetts.

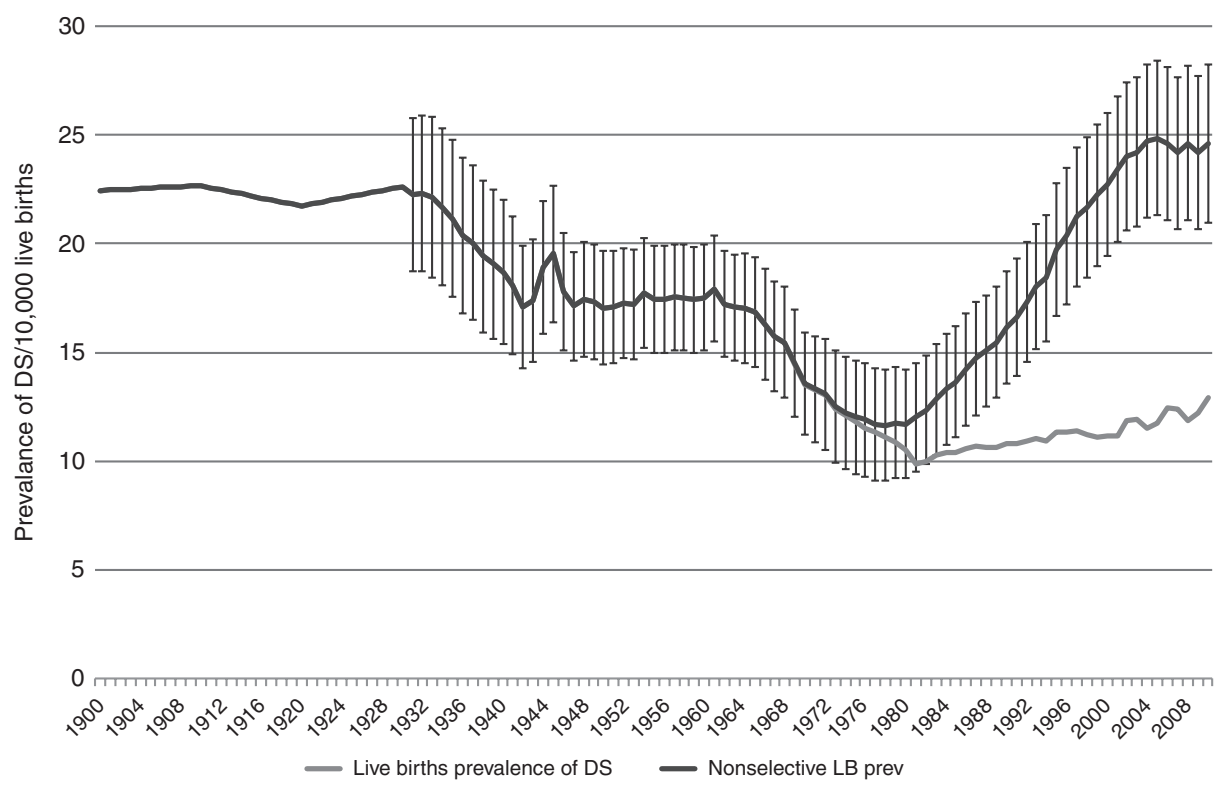

Figure 2 Estimated annual live birth prevalence for DS in MA during 1900-2010, and live birth prevalence if there were no DS-related elective terminations during 1969-2010. Error bars indicate 95\% confidence intervals. DS, Down syndrome; MA, Massachusetts.

live births higher or lower than estimated currently. The standard deviation (SD) of the estimated number of nonselective DS live births in MA $\left(x_{2}\right)$ can be approximated by the formula $Z \times \sqrt{\sum_{i=1, \ldots, n}\left[n_{2 i}\left(1+\frac{n_{2 i}}{n_{1 i}}\right) \times \frac{x_{1 i}}{n_{1 i}} \times\left(1-\frac{x_{1 i}}{n_{1 i}}\right)\right.}$ where $n_{2 i}$ is the total number of live births in MA per maternal age group, $n_{1 i}$ is the total number of live births per maternal age group in the sample of Morris et al., ${ }^{9} x_{1 i}$ is the number of live births with DS per maternal age group in the same sample, and $Z$ is the associated $Z$ score. Live birth estimates for 2000-2010 are based on full counts that we consider reliable. However, estimates for other years are based on extrapolating trends from reduction percentages.
Additional uncertainty in the estimates of DS-related terminations stems from our correction for natural losses. Using a Monte Carlo simulation with 10,000 iterations, we estimated the width of the $95 \%$ CI for recent years to be within $29 \%$ of the predicted number of DS-related terminations.

\section{DISCUSSION}

We provide estimates, not empirical counts, of live births, elective terminations, and natural losses for DS. The effect of systematically changing the value of input parameters (for instance, using different models of maternal age-related chances) has been described previously for the United States as a whole. ${ }^{7}$ These changes had only small effects on the outcome 
a

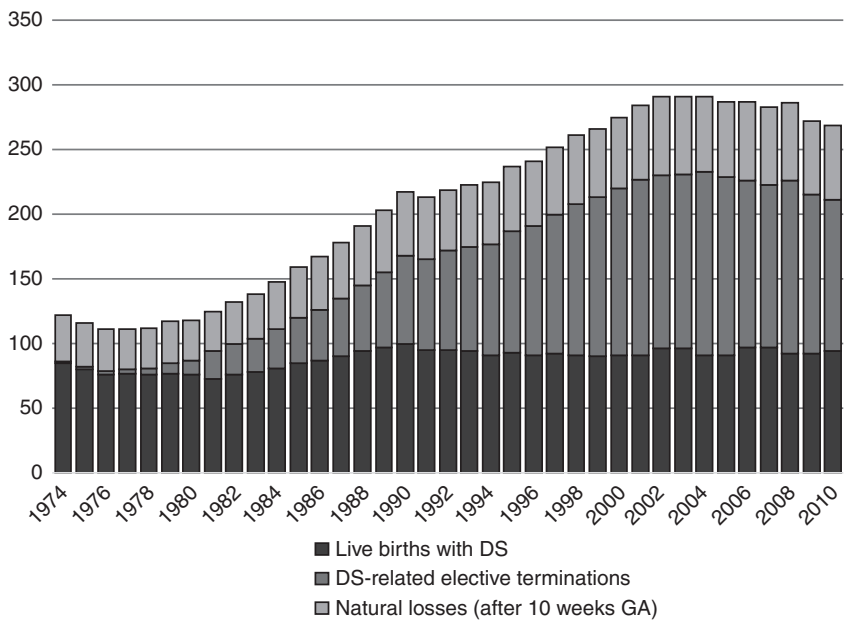

b

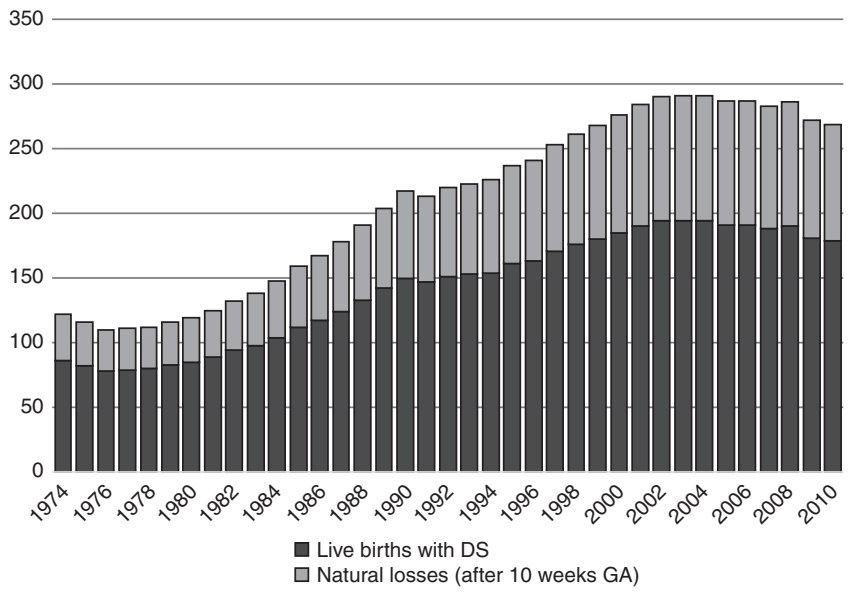

Figure 3 Annual estimates of the total number of DS fetuses at 10 weeks gestational age in MA during 1974-2010 and estimated pregnancy outcomes of live births with DS, elective pregnancy terminations of fetuses with DS, and natural losses from a gestational age of 10 weeks in two scenarios: (1) the current situation (a) and (2) a hypothetical situation if there were no DS-related elective pregnancy terminations (b). DS, Down syndrome; MA, Massachusetts.

Table 2 Estimates of nonselective and live birth prevalence of DS and reduction percentage in MA for 2006-2010

\begin{tabular}{lcrr} 
& $\begin{array}{c}\text { Estimates of nonselective live birth } \\
\text { prevalence of DS (per 10,000 live } \\
\text { births) }\end{array}$ & $\begin{array}{c}\text { Estimates of live birth } \\
\text { prevalence of DS (per 10,000 } \\
\text { live births) }\end{array}$ & $\begin{array}{c}\text { Estimated } \\
\text { reduction } \\
\text { percentage }\end{array}$ \\
\hline Asians/Pacific Islanders & $25.0(19.2-30.8)$ & $10.0(9.4-10.6)$ & $60.1 \%(50.0-70.2)$ \\
Non-Hispanic whites & $26.6(24.6-28.7)$ & $12.3(12.2-12.4)$ & $53.8 \%(50.2-57.5)$ \\
Non-Hispanic blacks/Africans & $22.4(17.3-27.4)$ & $15.8(15.1-16.5)$ & $29.4 \%(12.1-46.7)$ \\
Hispanics & $15.7(12.4-19.1)$ & $13.7(13.2-14.2)$ & $12.7 \%(0-32.8)$ \\
\hline
\end{tabular}

$95 \% \mathrm{Cl}$ in parentheses.

DS, Down syndrome; MA, Massachusetts.

variables. We did not perform a separate sensitivity analysis for MA because the magnitude of these changes will be the same.

The CI in our study are relatively wide. This is the consequence of the small total number of annual births in one state, which affects the reliability of the nonselective live birth prevalence estimations. In addition, the intervals for elective terminations are even wider because we have to estimate the number of elective terminations associated with the estimated number of births reduced (using a correction factor for natural loss). However, the 95\% CI for births reduced, and thus for reduction percentages, which is a crucial measure for evaluating the net effect of screening programs on live birth prevalence, are smaller-within $17 \%$ of the predicted values for recent years. A further narrowing of CIs can be achieved by analyzing 5 years taken together. For instance, the MA reduction percentage for 2006-2010 is approximately $49 \%$, with a $95 \%$ CI of 45.6-52.3.

For the period before 2000, we had to estimate the live birth prevalence in MA on the basis of the an extrapolation of trends in reduction percentages. However, our estimates of live birth prevalence for DS and the estimated reduction percentages for MA are similar to those found in the neighboring state of New York, which is culturally akin to MA. Researchers have reported a live birth prevalence for DS of 10.4 per 10,000 in New York during the period 1984-1992,22 our assumptions led to 10.6 per 10,000 for MA in the same period. Taking the difference between the expected number of live births with DS (applying a model for maternal age-related chances of a birth with DS to the maternal age distribution of births in the general population) and the actual counts of live-born children with DS, Olsen et al..$^{22}$ constructed a reduction percentage due to elective terminations of 34\% for New York in 1992. We modeled 37\% for MA in the same year (MA has a slightly higher maternal age than New York does). Between 1983 and 1997, live birth prevalence for DS in New York remained stable at approximately 9.9 per 10,000 live births $;{ }^{23}$ we modeled 10.8 per 10,000 for MA. According to Olsen et al., ${ }^{23}$ again based on the difference between expected births and actual counts, the reduction percentage was $42 \%$ in New York in 1995. We modeled 43\% for MA in 1995 . We think this similarity between our estimates and the findings from New York form an argument in favor of the validity of our assumptions.

\section{Nonselective live birth prevalence}

Between 1920 and 1940, the number of live births with DS decreased in MA; between 1930 and 1940, live birth prevalence 
decreased, too. From 1940 until 1957, total fertility rates increased..$^{24,25}$ Consequently, the total number of live births increased, and so did the total number of live births with DS in MA. With the exception of a small temporary peak between 1944 and 1945, the live birth prevalence for DS stayed fairly constant during 1940-1957 in MA, similar to that in the United States as a whole. ${ }^{7}$ In the 1960s, the birth control pill and the intrauterine device became available. ${ }^{24}$ Over the next two decades, there was a sharp decrease in the total number of live births and the total number of live births with DS in MA, similar to the numbers for the United States as a whole. ${ }^{7}$ Live birth prevalence for DS declined as well because of a decreasing number of older mothers. From the early 1980s onward, as a consequence of postponed motherhood, the percentage of mothers older than 35 years of age rose again, resulting in a clear increase in nonselective live birth prevalence for DS. In comparison with the United States as a whole, ${ }^{7}$ this trend is more evident in MA, a state with a higher proportion of women with high educational backgrounds, ${ }^{26}$ which is associated with postponed motherhood. ${ }^{27}$ For both the United States and MA, this development of increasing nonselective live birth prevalence for DS appears to plateau in most recent years.

\section{Live birth prevalence}

In the early 1970s, prenatal diagnoses had little influence on the live birth prevalence of DS. However, from the late 1970s onward, although nonselective live birth prevalence for DS greatly increased in MA, there was a small decrease in live birth prevalence for DS in MA in the late 1970s and a fairly constant rate during 1980-2000. Compared with that of the United States, ${ }^{7}$ the nonselective live birth prevalence increased in MA. However, so did the number of DS-related elective terminations, resulting in a live birth prevalence for DS that was slightly lower in MA than in the United States (12.4 per 10,000 births in MA vs. 12.6 per 10,000 in the United States in most recent years). MA had relatively older mothers, and older mothers tend to do more screening, as revealed by an analysis of reduction percentages by maternal age for the United States, as a whole and by region. ${ }^{7}$ However, there also appear to be cultural differences between states. In MA, as of 2007, we estimated the reduction percentage for women 35 years and older to be approximately $60 \%$ and that for younger women to be approximately $34 \%$. In the United States as a whole, as of 2007, the corresponding values were 43 and $18 \%$, respectively.?

In addition, there appear to be racial/ethnic differences in reduction percentages. In our analysis, reduction percentage estimates were highest among Asians/Pacific Islanders (60\%), followed by non-Hispanic whites (54\%), non-Hispanic blacks/ Africans (29\%), and Hispanics (13\%). A similar racial/ethnic trend was found in the analysis for the United States as a whole, ${ }^{7}$ with rates for these four groups being $61 \%, 39 \%, 27 \%$, and $18 \%$, respectively.

Finally, our estimate of live birth prevalence for 2010 for MA is approximately 1 in 810 live births, which is slightly lower than that in the United States as a whole ( 1 in 792)..$^{7}$ Our estimate of total case prevalence for MA-including live births, DS-related elective pregnancy terminations, and modeled natural loss (fetal loss and stillbirths) after the gestational age of 10 weeksis approximately 1 in 273 live births, which is clearly higher than the estimate for the United States as a whole ( 1 in 365). ${ }^{7}$ Nonselective live birth prevalence is higher in MA than in the United States. Reduction percentage for MA is estimated to be $49 \%$ (95\% CI: 45.6-52.3), which is much higher than the estimate of 30\% (95\% CI: 27.3-31.9) for the United States. ${ }^{7}$ The reduction percentage in MA is in line with the reduction of $55 \%$ reported for Australia (as of 2004), ${ }^{28} 48 \%$ reported for the United Kingdom (as of 2008), ${ }^{29}$ and 47\% reported for Slovenia (as of 2005). ${ }^{30}$

\section{Other US publications on DS in MA}

Shin et al. ${ }^{8}$ published information on live birth prevalence of children with DS in the United States, covering surveillance data from 1979 to 2003, with a focus on 1999-2003. However, MA was not one of the states included in their analysis. Canfield et al. ${ }^{31}$ estimated DS prevalence on the basis of surveillance data for 1999-2001; however, their estimate was not live birth prevalence, it was total prevalence (including counted elective terminations and natural losses). Parker et al. ${ }^{32}$ did the same for 2004-2006. Additionally, Parker et al. estimated live birth prevalence for DS separately, but on the basis of only three surveillance programs. MA was not in this analysis. Finally, Mai et al. ${ }^{19}$ estimated live birth prevalence for DS in the United States for 2006-2010 on the basis of 11 programs that only counted live births; MA was not one of these.

In the articles by Parker et al..$^{32}$ and Mai et al., ${ }^{19}$ an attempt was made to estimate separately the number of live births, natural losses, and elective terminations. However, the difference between the expected number of DS-related elective terminations (as derived on the basis of the methods used in the study by de Graaf et al. ${ }^{7}$ and in our current study) and the estimations by Parker et al. ${ }^{32}$ and Mai et al. ${ }^{19}$ (based on counts in surveillance programs) highlights the significant underreporting of elective terminations in these programs. A strategy that could lead to a much higher ascertainment might be the establishment of a National Down Syndrome Cytogenetic Register, as has been active in the United Kingdom since 1989, in which information is collected on both prenatal and postnatal karyotypes from all cytogenetic laboratories in the country and in which prenatal diagnoses are followed up for pregnancy outcome. ${ }^{9,29}$

\section{Conclusion}

Parents, clinicians, journalists, and elected officials often ask whether fewer babies with DS are born following the introduction of each new prenatal test. A complete answer involves a description of two trends: the number of live births with DS and the number of potential live births with DS without elective terminations. Since 1990, the number of babies with DS born in MA has remained relatively constant at approximately 93 per year. However, the number of conceptions with DS has increased because of changing cultural preferences among 
women in MA (e.g., postponement of motherhood). For the last years analyzed, 2006-2010, we estimated that 186 babies would have been born with DS in the absence of DS-related elective terminations. This means that approximately $49 \%$ of potential live births with DS were selectively terminated in MA during that period. Since 2011, noninvasive cell-free DNA testing for DS has become increasingly available to pregnant women in MA. ${ }^{33-36}$ An open question remains: how will these trends change, if at all, in the coming years?

\section{SUPPLEMENTARY MATERIAL}

Supplementary material is linked to the online version of the paper at http://www.nature.com/gim

\section{ACKNOWLEDGMENTS}

We thank Milt Kotelchuck for his consultation during the early phases of this project, Pieter van Casteren for his help with the statistical analyses, and Joan Morris for sharing details of her own statistical modeling.

\section{DISCLOSURE}

B.G.S. serves in an unpaid capacity on the board of directors or scientific advisory boards for the Massachusetts Down Syndrome Congress, the Band of Angels Foundation, and the National Center for Prenatal and Postnatal Down Syndrome Resources, all of which are nonprofit organizations. He is co-director of the Massachusetts General Hospital Down Syndrome Program and is occasionally remunerated from Down syndrome nonprofit organizations for speaking engagements about Down syndrome. He receives support for clinical drug trials involving people with Down syndrome from F. Hoffmann-La Roche, Ltd. He has a sister with Down syndrome. G.deG. works for the Dutch Down Syndrome Foundation, a nonprofit organization. He had a daughter with Down syndrome, who passed away in 2005 at the age of 15. F.B. works for Down Syndrome Education International and Down Syndrome Education USA. The charities receive donations and grants from individuals and organizations to conduct research and develop resources and services to improve early intervention and education for children with Down syndrome. He also serves in an unpaid capacity as vice president of the European Down Syndrome Association and as a member of the Professional Advisory Committee of the US National Center for Prenatal and Postnatal Down Syndrome Resources. He has a sister with Down syndrome.

\section{REFERENCES}

1. Massachusetts General Hospital. Down syndrome program. 2014. http://www. massgeneral.org/downsyndrome. Accessed 5 June 2014.

2. Massachusetts Down Syndrome Congress. Parents First Call. 2014. http://www. mdsc.org/programs/ParentsFirstCall.cfm. Accessed 5 June 2014

3. Massachusetts Down Syndrome Congress. Hosting Grand Rounds. 2014. http:// www.mdsc.org/programs/HostingGrandRounds.cfm. Accessed 5 June 2014.

4. Skotko B. Prenatal diagnoses of Down syndrome: delivering results in our new age of genetic testing. 2014. http://mghacademy.org/courses/course-detail/ prenatal_diagnoses_of_down_syndrome_delivering_results_in_our_new_ age. Accessed 5 June 2014.

5. Massachusetts Down Syndrome Congress. Landmark prenatal testing bill signed into law. 2012. http://www.mdsc.org/mdsc_Content/documents/ Prenatal_bill_signed_into_law.pdf. Accessed 5 June 2014.
6. Lettercase. Understanding a Down syndrome diagnosis. 2014. http://www. lettercase.org. Accessed 5 June 2014.

7. de Graaf G, Buckley F, Skotko BG. Estimates of the live births, natural losses, and elective terminations with Down syndrome in the United States. Am J Med Genet A 2015;167A:756-767.

8. Shin M, Besser LM, Kucik JE, Lu C, Siffel C, Correa A; Congenital Anomaly Multistate Prevalence and Survival Collaborative. Prevalence of Down syndrome among children and adolescents in 10 regions of the United States. Pediatrics 2009;124:1565-1571.

9. Morris JK, Mutton DE, Alberman E. Revised estimates of the maternal age specific live birth prevalence of Down's syndrome. J Med Screen 2002;9:2-6.

10. Savva GM, Morris JK. Ascertainment and accuracy of Down syndrome cases reported in congenital anomaly registers in England and Wales. Arch Dis Child Fetal Neonatal Ed 2009;94:F23-F27.

11. de Graaf G, Haveman M, Hochstenbach $R$, et al. Changes in yearly birth prevalence rates of children with Down syndrome in the period 1986-2007 in The Netherlands. J Intellect Disabil Res 2011;55:462-473.

12. Bishop J, Huether CA, Torfs C, Lorey F, Deddens J. Epidemiologic study of Down syndrome in a racially diverse California population, 1989-1991. Am J Epidemiol 1997;145:134-147.

13. Carothers AD, Hecht CA, Hook EB. International variation in reported livebirth prevalence rates of Down syndrome, adjusted for maternal age. J Med Genet 1999;36:386-393

14. Forrester MB, Merz RD. Maternal age-specific Down syndrome rates by maternal race/ethnicity, Hawaii, 1986-2000. Birth Defects Res A Clin Mol Teratol 2003:67:625-629.

15. Hook EB, Carothers AD, Hecht CA. Elevated maternal age-specific rates of Down syndrome liveborn offspring of women of Mexican and Central American origin in California. Prenat Diagn 1999;19:245-251.

16. Huether CA, Ivanovich J, Goodwin BS, et al. Maternal age specific risk rate estimates for Down syndrome among live births in whites and other races from Ohio and metropolitan Atlanta, 1970-1989. J Med Genet 1998;35:482-490.

17. Khoshnood B, Pryde P, Wall S, Singh J, Mittendorf R, Lee KS. Ethnic differences in the impact of advanced maternal age on birth prevalence of Down syndrome. Am J Public Health 2000;90:1778-1781.

18. Office for National Statistics. 2011 Census for England and Wales. 2011. http:// www.ons.gov.uk/ons/guide-method/census/2011/how-our-census-works/ how-did-we-do-in-2011-/2011-census-general-report/2011-census-generalreport--full-report.pdf. Accessed 31 October 2015.

19. Mai CT, Kucik JE, Isenburg J, et al.; National Birth Defects Prevention Network. Selected birth defects data from population-based birth defects surveillance programs in the United States, 2006 to 2010: featuring trisomy conditions. Birth Defects Res A Clin Mol Teratol 2013;97:709-725.

20. Morris JK, Wald NJ, Watt HC. Fetal loss in Down syndrome pregnancies. Prenat Diagn 1999;19:142-145.

21. Savva GM, Morris JK, Mutton DE, Alberman E. Maternal age-specific fetal loss rates in Down syndrome pregnancies. Prenat Diagn 2006;26:499-504.

22. Olsen CL, Cross PK, Gensburg $\sqcup$, Hughes JP. The effects of prenatal diagnosis, population ageing, and changing fertility rates on the live birth prevalence of Down syndrome in New York State, 1983-1992. Prenat Diagn 1996;16: 991-1002.

23. Olsen CL, Cross PK, Gensburg L. Down syndrome: interaction between culture, demography, and biology in determining the prevalence of a genetic trait. Hum Biol 2003; 75:503-520.

24. Centers for Disease Control and Prevention. Achievements in public health 1900-1999: family planning. Morb Mortal Wkly Rep. 1999;48:1073-1080.

25. Wetzel JR. American families: 75 years of change. Mon Labor Rev. 1990;113 $4-13$.

26. US Census Bureau. Statistical abstract of the United States. Table 233. 2012. http://www.census.gov/library/publications/2011/compendia/statab/131ed/ education.html. Accessed 6 November 2015.

27. Mills M, Rindfuss RR, McDonald P, te Velde E; ESHRE Reproduction and Society Task Force. Why do people postpone parenthood? Reasons and social policy incentives. Hum Reprod Update 2011;17:848-860.

28. Bittles $A H$, Bower $C$, Hussain R, Glasson EJ. The four ages of Down syndrome. Eur J Public Health 2007;17:221-225.

29. Morris JK, Alberman E. Trends in Down's syndrome live births and antenatal diagnoses in England and Wales from 1989 to 2008: analysis of data from the National Down Syndrome Cytogenetic Register. BMJ. 2009;339:b3794.

30. Tul N, Verdenik I, Premru Srsen T, Novak Antolic Z. Incidence of Down syndrome in Slovenia in the last 15 years. Ultrasound Obstet Gynecol. 2007;30: 569-570. 


\section{ORIGINAL RESEARCH ARTICLE}

31. Canfield MA, Honein MA, Yuskiv N, et al. National estimates and race/ethnicspecific variation of selected birth defects in the United States, 1999-2001. Birth Defects Res A Clin Mol Teratol 2006;76:747-756.

32. Parker SE, Mai CT, Canfield MA, et al.; National Birth Defects Prevention Network. Updated National Birth Prevalence estimates for selected birth defects in the United States, 2004-2006. Birth Defects Res A Clin Mol Teratol 2010;88:1008-1016.

33. Palomaki GE, Kloza EM, Lambert-Messerlian GM, et al. DNA sequencing of maternal plasma to detect Down syndrome: an international clinical validation study. Genet Med 2011;13:913-920.
34. Norton ME, Brar H, Weiss J, et al. Non-Invasive Chromosomal Evaluation (NICE) Study: results of a multicenter prospective cohort study for detection of fetal trisomy 21 and trisomy 18. Am J Obstet Gynecol 2012;207:137.e1-137.e8.

35. Bianchi DW, Platt LD, Goldberg JD, Abuhamad AZ, Sehnert AJ, Rava RP; MatErnal BLood IS Source to Accurately diagnose fetal aneuploidy (MELISSA) Study Group. Genome-wide fetal aneuploidy detection by maternal plasma DNA sequencing. Obstet Gynecol 2012;119:890-901.

36. Nicolaides KH, Syngelaki A, Ashoor G, Birdir C, Touzet G. Noninvasive prenatal testing for fetal trisomies in a routinely screened first-trimester population. $A m$ J Obstet Gynecol 2012;207:374.e1-374.e6. 